\title{
Are You Too Burnt Out to Read This? I Expect Not
}

\author{
Murray F. Brennan, MD \\ Memorial Sloan-Kettering Cancer Center, New York, NY
}

In the current issue of the Annals, Balch and colleagues summarize burnout and career satisfaction among surgical oncologists compared with other surgical specialties. ${ }^{1}$ This is a follow-up from their survey looking at all surgeons published in 2009 and a follow-up to the previous report by Kuerer looking at members of the Society of Surgical Oncology in 2007.,3 Overall, $40 \%$ of surgeons responding to the 2008 American College of Surgeons (ACS) survey met the criteria for burnout, $30 \%$ screened positive for depression, and $28 \%$ had a mental quality of life score at least half a standard deviation below that of the US population. ${ }^{4}$ I was encouraged to see that only $20 \%$ had been involved in divorce, when the national average approximates $50 \%$. Perhaps we do better because the high divorce rate is seen in those married before age 24 years (38\%). Perhaps our divorce rate is low because, of those who do divorce in the USA, $80 \%$ were married before the age of 30 years. One wonders what the average age of marriage was in this cohort.

There is some confusion in Table 2, as it suggests that the median work week is $60 \mathrm{~h}$, but also lists that $73 \%$ worked greater than $60 \mathrm{~h}$. We do work hard, but that too is not a cause for burnout and dissatisfaction. Even though $50 \%$ of participants suggest that they do not have enough personal time, $75 \%$ would be a surgeon again and $60 \%$ would have their children become a surgeon. In some ways we seem to be a rather balanced lot. Where work demands conflict with personal time, $50 \%$ were able to work it out to mutual satisfaction. A lot of this comes down to: is the glass half full or half empty?

As an Ex-Chairman, what was I missing? Did I really have a department where one in three of the surgeons were

(C) Society of Surgical Oncology 2010

First Received: 14 September 2010; Published Online: 16 October 2010

M. F. Brennan, MD

e-mail: brennanm@mskcc.org burnt out? Were 1 in 3 really depressed, and did 1 in 20 have serious suicidal ideation? I must have been blissfully unaware; or is the explanation that these frightening concerns did not translate into frightening failures or chronic discontent? Some of these observations may be cynically explained. If $54 \%$ had children between the ages of 5 and 22 years, who has not had a transient period of dissatisfaction/depression with a teenage child, or more than one?

In defense of my failure to recognize this high degree of pathological attitudes in my staff, I have to find some explanation if I am not to be defined as a complete failure as a leader. I assume that I filled out this survey, but I did not keep a copy of what I said at the time. Have I ever been depressed? Of course, but it has been remarkably transient; how did I record that? When did I fill out the survey? As surveys are not high on my list of priorities, it was probably late in the evening, certainly not my best time. Perhaps the timing was such that it was almost exactly when I concluded that the administrative demands were not worth the aggravation. How different it is to fill out a survey late on a Friday evening when trying to leave to spend some family time, if you just received a complaint from one of the nonmedical staff about an inappropriate gesture by one of your surgeons, versus reading a heartfelt letter thanking you for the time and effort you put into a patient the outcome of which was poor.

Was my career a failure because I was transiently depressed, at least for a few minutes or so? Was my Chairmanship a failure because I did not recognize the enormous number of my staff that were burnt out? I agree with the authors that we should be more sensitive and empathetic to the needs of our staff. For me personally, the addition of a squash court to the clinical building rather than three rooms for the Compliance Office or where I could get psychosocial help would have been preferable (of course I could play squash at any time; psychosocial help came from 9 to 5 most days). No one ever quite understood 
me when I said that I was off to see my black psychiatrist as I picked up my squash gear. Did I really imagine that that little black ball was one of my lesser-performing residents or fellows, or some administrative person who had pointed out my failures in compliance? I expect not consciously, but it certainly helped.

None of my children went into medicine despite both parents being physicians, so that says something about what they thought of our lifestyle. However, would I have encouraged them if they had wished to go into medicine? Of course! Am I even remotely disappointed that one did not? Perhaps. I think at least one of them would have made a fine physician, but that is not what they chose to do.

How do I put all of this together? I do think these surveys are interesting and in the main important, but I do struggle with overinterpretation of emotional responses at a specific moment in time. I do struggle with the fact that surgery is a challenge, but it is also extraordinarily rewarding. How do I balance the stresses with the rewards? I think it is a bell-shaped curve, which is time related. In the early parts of one's career, one is frustrated by the hours as a resident, failure to get a grant, aggravations of promotion or lack thereof, and unfulfilled family demands; and in the latter part of the curve with the rewards of achievement, the ability to be inspired by young people in training, a grown family, and so many grateful patients. The challenge is never to let that bell-shaped curve come to an apex, where it exceeds the depression threshold and requires drugs or alcohol, divorce or suicidal inclination. Most interpersonal relationships fail because of unmet expectations. The current generation of surgeons is an impressive lot; they seem to have more clearly defined expectations than my generation. In so doing, they balance the stimulus of stress with the high rewards that we all are privileged to enjoy.

\section{REFERENCES}

1. Balch C, Shanafelt T, Sloan J, Satele D, Juerer H. Burnout and career satisfaction among surgical oncologists compared with other surgical specialties. Ann Surg Oncol. 2010.

2. Balch CM, Freischlag JA, Shanafelt TD. Stress and burnout among surgeons: understanding and managing the syndrome and avoiding the adverse consequences. Arch Surg. 2009;144(4):371-6.

3. Kuerer HM, Eberlein TJ, Pollock RE, Huschka M, Baile WF, Morrow M, et al. Career satisfaction, practice patterns and burnout among surgical oncologists: report on the quality of life of members of the Society of Surgical Oncology. Ann Surg Oncol. 2007;14(11):3043-53.

4. Shanafelt TD, Balch CM, Bechamps GJ, Russell T, Dyrbye L, Satele D, et al. Burnout and career satisfaction among American surgeons. Ann Surg. 2009;250(3):463-71. 